\title{
TITLE:
}

\section{Characterization of lignin-derived products from Japanese beech wood as treated by two-step semi- flow hot-compressed water}

\section{$\operatorname{AUTHOR}(\mathrm{S})$ :}

Yamauchi, Kazuchika; Phaiboonsilpa, Natthanon; Kawamoto, Haruo; Saka, Shiro

\section{CITATION:}

Yamauchi, Kazuchika ... [et al]. Characterization of lignin-derived products from Japanese beech wood as treated by two-step semi-flow hot-compressed water. Journal of Wood Science 2013, 59(2): 149-154

\section{ISSUE DATE:}

2013-04

URL:

http://hdl.handle.net/2433/187117

\section{RIGHT:}

The final publication is available at link.springer.com; この論文は出版 社版でありません。引用の際には出版社版をご確認ご利用ください。; This is not the published version. Please cite only the published version. 
Characterization of lignin-derived products from Japanese beech wood as treated by two-step semi-flow hot-compressed water

Original paper

Kazuchika Yamauchi, Natthanon Phaiboonsilpa, Haruo Kawamoto and Shiro Saka* Graduate School of Energy Science, Kyoto University, Japan *Corresponding author

Department of Socio-Environmental Energy Science, Graduate School of Energy

Science, Kyoto University, Yoshida-honmachi, Sakyo-ku, Kyoto, 606-8501, Japan E-mail: saka@energy.kyoto-u.ac.jp, Tel/Fax: +81-75-753-4738

Keywords: lignin, Japanese beech, hot-compressed water, lignin-derived product

Footnote: This study was presented in part at the 55th Annual Meeting of the Japan Wood Research Society, Matsumoto, Japan, March 15-17, 2009, and 54th Lignin Symposium, Shizuoka, Japan, October 28-29, 2009. 


\section{Abstract}

Japanese beech (Fagus crenata) wood was treated by two-step semi-flow hot-compressed water (the first stage: $230^{\circ} \mathrm{C} / 10 \mathrm{MPa} / 15 \mathrm{~min}$, the second stage: $270^{\circ} \mathrm{C} / 10 \mathrm{MPa} / 15 \mathrm{~min}$ ), and produced lignin-derived products in the hot-compressed water-soluble portions at the first and second stages, and the final residue of the second stage were characterized with alkaline nitrobenzene oxidation method and gel-permeation chromatographic analysis. As a result, the lignin-derived products at the first stage, where hemicellulose was also decomposed, consisted of lignin-based monomers and dimers and oligomers/polymers in the water-soluble portion. A large part of the oligomers/polymers was, however, recovered as the precipitate during $12 \mathrm{~h}$ setting after hot-compressed water treatment. By the analysis of nitrobenzene oxidation products, there were relatively higher contents of ether-type lignin in the precipitate at the first stage than in original beech wood. Since the ether-linkages of lignin are more preferentially cleaved by this hot-compressed water, lignin-based polymeric fractions were flowed out from the porous cell walls from which hemicellulose was removed. On the other hand, at the second stage condensed-type lignin remained in the precipitate and residue. Based on these results, decomposition behavior of lignin in Japanese beech wood as treated by the two-step semi-flow hot-compressed water was discussed 
regarding the topochemistry of lignin structure. 


\section{Introduction}

Bioethanol from lignocellulosics has recently been attracted as an alternative liquid fuel for gasoline engine. Since lignocellulosics is the most abundant biomass resource on the earth, bioethanol from lignocellulosics can play an important role in mitigating the greenhouse gas emission ${ }^{1,2}$ and developing the sustainable society for the future $^{3}$. Different from molasses and starch, lignocellulosics is a composite material of cellulose, hemicellulose and $\operatorname{lignin}^{4}$. Cellulose and hemicellulose are polysaccharides which can be converted into fermentable sugars for bioethanol production. On the other hand, lignin, which is an aromatic polymer consisting of phenylpropane units, cannot be utilized for ethanol fermentation. For the conventional bioethanol production from lignocellulosics, it is necessary for a "pre-treatment" to remove lignin for saccharification.

In recent bioethanol production, acid hydrolysis with sulfuric acid has been used most frequently for saccharification and removal of lignin from lignocellulosics ${ }^{5-8}$. In this acid hydrolysis process, lignin is separated as the precipitate from the water-soluble sugars. However, the lignin-derived products from the sulfuric acid hydrolysis have been reported to have extensively condensed structures ${ }^{9}$. From a viewpoint of lignin utilization, such extensively degraded and condensed lignin would 
be difficult to be utilized as value-added products. In fact, utilization of the sulfuric acid lignin is considered just for only thermal recycling ${ }^{5}$.

Chemical structure of lignin is known to be different, depending on the type of lignocellulosics. Although softwood lignin contains mainly guaiacyl-type of aromatic ring, hardwood lignin has syringyl-type as well as guaiacyl-type ${ }^{10}$. Such different aromatic ring composition also leads to the different composition of the linkage types of the phenylpropane units. Usually hardwood lignin contains less condensed-types of lignin than softwood lignin ${ }^{10}$.

Our previous study described the decomposition behavior of Japanese beech wood in two-step semi-flow hydrolysis in hot-compressed water treatment (the first stage: $230^{\circ} \mathrm{C} / 10 \mathrm{MPa} / 15 \mathrm{~min}$, the second stage: $\left.270^{\circ} \mathrm{C} / 10 \mathrm{MPa} / 15 \mathrm{~min}\right)^{11}$. Hemicellulose and cellulose were decomposed at the first and second stages, respectively. Interestingly, based on the Klason lignin (KL) content of the residue at the first stage, a large part of lignin was decomposed to be the hot-compressed water-soluble products. Several monomers and condensed-type of dimers were identified in its soluble portion by gas chromatography-mass spectrometry (GC-MS) analysis ${ }^{11}$. Based on these results in our previous paper, beech lignin might be degraded and solubilized into low molecular weight compounds without any chemical modification. This suggests that the 
lignin-derived products from the hot-compressed water treatment may remain as a natural lignin structures in their remaining linkages. However, the lignin-derived products have not been fully characterized yet.

In this paper, therefore, the lignin-derived products, which were recovered as water-soluble portions and precipitates at the first and second stages, respectively, were characterized with the alkaline nitrobenzene oxidation and gel-permeation chromatographic (GPC) methods. Decomposition behavior of lignin in Japanese beech wood was also discussed during hot-compressed water treatment. Because this is non-catalytic treatment, obtained lignin-derived products seemed to be less chemically denatured. These results will be useful not only for effective utilization of lignin as a by-product, such as a chemical and plastic material, but also for study on the nature of lignin chemical structures.

\section{Materials and methods}

\section{Wood sample and chemicals}

Japanese beech (Fagus crenata) wood flour (18 mesh-passed) was used for hot-compressed water treatment. The wood flour was extracted with ethanol-benzene $(1: 2 \mathrm{v} / \mathrm{v})$ mixture by using Soxhlet apparatus, and dried at $105^{\circ} \mathrm{C}$ for $24 \mathrm{~h}$ before use. The 
chemical composition of the extractive-free Japanese beech wood was $44.8 \mathrm{wt} \%$ of cellulose, $28.7 \mathrm{wt} \%$ of hemicellulose and $26.5 \mathrm{wt} \%$ of lignin ${ }^{12}$. All chemicals used in this study were purchased as reagent-grades and used without further purification.

\section{Hot-compressed water treatment and fractionation of the products}

The two-step semi-flow hot-compressed water treatment conditions were $230^{\circ} \mathrm{C} / 10 \mathrm{MPa} / 15 \mathrm{~min}$ for the first stage and $270^{\circ} \mathrm{C} / 10 \mathrm{MPa} / 15 \mathrm{~min}$ for the second stage as reported in the previous paper ${ }^{11}$. Flow-rate of hot-compressed water was $10 \mathrm{~mL} / \mathrm{min}$, and the hot-compressed water-soluble products were collected continuously, as shown in Fig. 1. After 12h, some insoluble substances were formed from the hot-compressed water-soluble portions, and these are recovered as the precipitates by filtration with filter (pore size: $0.2 \mu \mathrm{m}$ ). Consequently, the hot-compressed water-soluble portions from the first and second stages were further fractionated into two fractions, i.e., water-soluble portion and precipitates, respectively, as illustrated in Fig. 1. The obtained water-soluble portions were freeze-dried, and the precipitates and residues were dried in a vacuum desiccator on dried silica gel. These dried fractions were weighed to determine their yields. 


\section{Analytical methods}

Yields of the lignin-derived products in fractions were determined as the combined yields of Klason lignin (KL) and acid-soluble lignin (ASL) ${ }^{13}$. Alkaline nitrobenzene oxidation was conducted for the precipitates and residues obtained from the first and second stages according to the standard method ${ }^{14}$.

Molecular weight (MW) distribution was evaluated for the water-soluble portions and the precipitates by GPC analysis, which was conducted on a LC-10A (Shimadzu, Kyoto, Japan) under the chromatographic conditions of column: Shodex KF-801 + KF-802 + KF-802.5 + KF-803 (Showa Denko, Tokyo Japan), eluent: tetrahydrofuran (THF), flow-rate: $0.6 \mathrm{~mL} / \mathrm{min}$, column temperature: $50^{\circ} \mathrm{C}$ and detector: UV: $205 \mathrm{~nm}^{15}$. For GPC analysis, the lignin-derived products in the water-soluble portions were extracted with ethyl acetate, and the precipitates were dissolved with THF in a sonicator for $10 \mathrm{~min}$.

\section{Results and discussion}

\section{Recovery of the lignin-derived products}

Yields of the fractionated products on oven-dried wood basis of Japanese beech wood as treated by the two-step semi-flow hot-compressed water are shown in Fig. 2. At the first 
stage, $54.1 \mathrm{wt} \%(=45.1 \mathrm{wt} \%+9.0 \mathrm{wt} \%)$ of the hot-compressed water-soluble products and $46.6 \mathrm{wt} \%$ of residue, which remained in the reaction cell, were obtained. The residue was further converted into the hot-compressed water-soluble products $(35.6 \mathrm{wt} \%=$ $30.3 \mathrm{wt} \%+5.3 \mathrm{wt} \%)$ at the second stage. The final residue at the second stage was only 4.4wt $\%$. From the hot-compressed water-soluble portions obtained at the first and second stages, $9.0 \mathrm{wt} \%$ and $5.3 \mathrm{wt} \%$ of the precipitates were recovered, respectively, after12h setting. Since the dielectric constant of water is known to decrease with the increasing temperature and pressure ${ }^{16}$, solubility of the products in hot-compressed water becomes different from that of ordinary water. Such solubility change may be a reason for the formation of the precipitates from the water-soluble products.

The percentage of the lignin-derived products in the fractionated portion was also shown in the values in parentheses in Fig. 2. In the water-soluble portion at the first stage, the value was only $19.7 \mathrm{wt} \%$, since hydrophobic lignin-derived products, which were soluble in hot-compressed water, were separated as their precipitates in the ordinary water. Interestingly, $91.0 \mathrm{wt} \%$ of the precipitate was found to be the lignin-derived products. Consequently, one third of lignin can be obtained as the precipitate at the first stage with high purity. Unlike the first stage, the content of the lignin-derived products in the precipitate at the second stage $(34.0 \mathrm{wt} \%)$ was 
comparatively low. Oligocellosaccharides were the other major constituents of the precipitate after $12 \mathrm{~h}$ setting, which are reported to be produced from cellulose $\mathrm{e}^{11}$.

The yields of the lignin-derived products on original lignin basis were shown in Fig. 3. The lignin contents were determined as the sum of KL and ASL in these fractionated products. At the first stage, two third of lignin $(64.4 \mathrm{wt} \%)$ was recovered as lignin-derived products in the hot-compressed water-soluble portion, which was further fractionated into the water-soluble products $(33.5 \mathrm{wt} \%)$ and the precipitate $(30.9 \mathrm{wt} \%)$, as shown in Fig. 3. Lignin remained in the residue at the first stage, $40.8 \mathrm{wt} \%$, was further treated at the second stage and converted into the hot-compressed water-soluble products $(30.3 \mathrm{wt} \%)$, which were further fractionated into the water-soluble products $(23.6 \mathrm{wt} \%)$ and the precipitate $(6.7 \mathrm{wt} \%)$. However, in the water-soluble products, only 7.4wt \% of lignin-derived products was detected by Klason method. These yields are much lower than those of the first stage. About $16.2 \mathrm{wt} \%$ of remaining lignin in the water-soluble products might be decomposed into low molecular weight compounds in the second stage reaction ${ }^{17}$. Furthermore, one tenth of lignin $(10.5 \mathrm{wt} \%)$ still remained in the final residue.

In a series of our previous studies, hardwood and softwood were treated in supercritical and subcritical water with batch-type reaction vessel, and lignin-derived 
products were recovered as water-insoluble and oily substances ${ }^{15,18,19}$. Because most of these substances were soluble in methanol, methanol was used as a solvent to isolate the lignin-derived products in the previous studies. In present paper, however, no oily substances were observed in the water-soluble portion. Because semi-flow system used much abundant water than batch-type reaction vessel, decomposed lignin-derived products might be too dilute to generate oily substances. Moreover, because decomposed products of Japanese beech wood were flowed out constantly from the reaction cell in semi-flow system, it might be difficult for the lignin-derived products to be cohere as oily substances form. In this study, to extract the lignin-derived products dissolved in the water-soluble portions directly, ethyl acetate was used as a solvent instead of methanol.

\section{Characterization of the lignin-derived products}

Gel-permeation chromatograms obtained for the lignin-derived products in the water-soluble portions and the precipitates are shown in Fig. 4. The MW profiles are quite different between the water-soluble portions and the precipitates. In both the first and the second stages, the lignin-derived products in the precipitates are observed in higher MW region (300-5000, polystyrene standard) than those (200-2000) of the 
water-soluble portions. Higher MW products with more hydrophobic character would precipitate from their aqueous solution with increasing the dielectric constant of water during $12 \mathrm{~h}$ setting ${ }^{16}$.

As for the low MW products in the water-soluble portion at the first stage, several monomers (coniferyl alcohol and sinapyl alcohol), dimers (diarylpropane and syringaresinol) and other low MW compounds such as vanillin and syringaldehyde have been identified in the previous paper ${ }^{11}$. Yields of these products were quite low at the second stage. Furfural and 5-hydroxymethyl furfural (5-HMF) were also identified in the water-soluble portions, which are formed from hemicellulose and cellulose.

Figure 5 shows the yields of alkaline nitrobenzene oxidation products for the fractionated products (mmol/g of lignin-derived product). Just for comparison, the yield for untreated wood was also included. The amount of lignin-derived products was evaluated as the sum of KL and ASL. The syringaldehyde/vanillin (S/V) ratio is also shown in the parentheses. Although the products obtained at the first stage gave some oxidation products, the yield was quite low to be almost null at the second stage. These results indicate that different chemical structures exist for the lignin-derived products at the first and the second stages. It is known that vanillin and syringaldehyde are formed only from the non-condensed types of guaiacyl- and syringyl-units, respectively, since 
this oxidation reaction cannot be involved in cleaving the condensed C-C-linkages of lignin. Consequently, the present results clearly show that the lignin-derived products obtained at the second stage have highly condensed structures of lignin.

At the first stage, the yield of nitrobenzene oxidation products $(4.42 \mathrm{mmol} / \mathrm{g}$ of lignin-derived product) from the precipitate was rather greater than that of $2.30 \mathrm{mmol} / \mathrm{g}$ of the original beech wood lignin. In contrast, its yield of $0.52 \mathrm{mmol} / \mathrm{g}$ from the residue at the first stage was much lower than that of the original lignin. The S/V ratios 2.6 for the precipitate and 1.3 for the residue at the first stage are also different from 2.3 for the untreated beech wood. The precipitate in the first stage includes syringyl-rich lignin-derived products, while the lignin remaining in the residue at the first stage has more guaiacyl-units than the original lignin. This is also consistent with the yields of ASL: its yield of $7.5 \mathrm{wt} \%$ on lignin basis in original lignin, $8.0 \mathrm{wt} \%$ of that in the precipitate at the first stage was larger than $1.2 \mathrm{wt} \%$ of that in the residue at the first stage (data not shown). It is known that syringyl-rich lignin gives more ASL in analysis with the Klason method ${ }^{10}$.

Monomers and dimers observed in the water-soluble portion at the first stage are the products after extensive cleavage of the ether-linkages. In model compound study, a phenolic $\beta$-ether type of dimer has been reported to be more reactive in 
cleavage of the ether-linkage than corresponding non-phenolic one in supercritical water $^{18}$ and supercritical methanol ${ }^{20}$. Condensed-types are also reported to be stable under such conditions.

The precipitate at the first stage and the monomers and dimers in the water-soluble portion at the first stage would be quite interesting materials for utilization of lignin. As already described, sulfuric acid lignin with highly condensed structures is quite difficult to be utilized as value-added materials. Contrary to this, the lignin-derived products obtained as the precipitate at the first stage in the present two-step hot-compressed water treatment have much simpler in chemical structures, in which the major interphenylpropane-linkages are the ether-types.

\section{Degradation behavior of lignin}

About two third and one third of lignin of Japanese beech wood were, respectively, decomposed as the hot-compressed water-soluble products at the first and second stages. Interestingly, the chemical structures of these two kinds of lignin-derived products were also quite different. At the first stage, monomers and dimers in the water-soluble portion and oligomers/polymers in the precipitate were identified as the lignin-derived products. Furthermore, the content of the ether-types of linkages and the S/V ratio were much 
higher in the oligomers/polymers than those of the original lignin in wood. In contrast, highly condensed lignins were recovered as the precipitate and the residue at the second stage.

These observations indicate that a topochemical effect of lignin ${ }^{21}$ exists in relation to the porosity of the cell wall for semi-flow type decomposition. In this semi-flow hot-compressed water treatment, hemicellulose is hydrolyzed and decomposed at the first stage. Thus, the porosity of the cell wall is increased. In the meanwhile, lignin macromolecules are decomposed in the ether-types of linkages. Consequently, a part of lignin which is rich in the ether-types of the interphenylpropane-linkages is solubilized into hot-compressed water through a small hole of hemicelluloses in the semi-flow system, before extensive cleavage of the ether-linkages occurs. This is perhaps the reason why the lignin-derived products in the precipitate at the first stage have more ether- and less condensed-type of linkages than the original wood lignin. Such a topochemical mechanism leaves the residue at the first stage with more condensed- and less ether-types of linkages. 


\section{Conclusions}

Lignin-derived products were obtained from Japanese beech wood treated by the two-step semi-flow hot-compressed water. Two third of lignin was degraded at the first stage of the treatment, where hemicellulose is hydrolyzed. Monomers, condensed-types of dimers, and a large amount of oligomers/polymers were characterized as the lignin-derived products at this stage of the treatment. Interestingly, the oligomers/polymers had much more ether-type of linkages than original lignin. On the other hand, lignin-derived products in the second stage of the treatment, where cellulose is hydrolyzed, had highly condensed structures. In addition, the residue after the second stage had also condensed structure of lignin. Based on these results, it may be suggested that topochemistry of lignin and relationship to the porosity of cell wall for the semi-flow treatment. Monomers and condensed-type of dimers are the products formed through extensive cleavage of the ether-linkages starting from the phenolic end-groups. The lignin-derived products obtained at this first stage, which have much simpler in chemical structures than sulfuric acid lignin, must be valuable materials for useful chemicals and value-added materials. 


\section{Acknowledgements}

This work has been done as the NEDO project (FYs2007-2010) "Eco-ethanol production from lignocellulosics with hot-compressed water treatment followed by acetic acid fermentation and hydrogenolysis", and has been continued as JST project (FYs2010-2012) "Ethanol Production with Acetic Acid Fermentation from Lignocellulosics", for all of which the authors are highly acknowledged.

\section{References}

1. Yuan JS, Tiller KH, Al-Ahmad H, Stewart NR, Stewart CN (2008) Plants to power: bioenergy to fuel the future. Trends Plant Sci 13: 421-429

2. Farrell AE, Plevin RJ, Turner BT, Jones AD, O'Hare M, Kammen DM (2006) Ethanol can contribute to energy and environmental goals. Science 311: 506-508

3. Hoogwijk H, Faaij A, van den Broek R, Berndes G, Gielen D, Turkenburg W (2003) Exploration of the ranges of the global potential of biomass for energy. Biomass Bioenergy 25: 119-133

4. Saka S (2000) Chemical composition and distribution. In: Hon DNS, Shiraishi N (ed) Wood and Cellulosic Chemistry (Second edition). Marcel Dekker, Inc, New York, pp $51-81$ 
5. Wyman CE (1994) Ethanol from lignocellulosic biomass: technology, economics, and opportunities. Bioresour Technol 50: 3-16

6. Kim KH, Tucker MP, Nguyen QA (2002) Effects of pressing lignocellulosic biomass on sugar yield in two-stage dilute-acid hydrolysis process. Biotechnol Prog 18: 489-494

7. Galbe M, Zacchi G (2002) A review of the production of ethanol from softwood. Appl Microbiol Biotechnol 59: 618-628

8. Kumar S, Singh SP, Mishra IM, Adhikari DK (2009) Recent advances in production of bioethanol from lignocellulosic biomass. Chem Eng Technol 32: 517-526

9. Yasuda S, Hirano J (1990) Chemical structures of sulfuric acid lignin XI. Physical and chemical properties of beech sulfuric acid lignin. Mokuzai Gakkaishi 36: 454-459

10. Sakakibara A and Sano Y (2000) Chemistry in lignin. In: Hon DNS, Shiraishi N (ed) Wood and Cellulosic Chemistry (Second edition). Marcel Dekker, Inc, New York, pp $109-173$

11. Lu X, Yamauchi K, Phaiboonsilpa N, Saka S (2009) Two-step hydrolysis of Japanese beech as treated by semi-flow hot-compressed water. J Wood Sci $55: 367-375$ 
12. Phaiboonsilpa N, Lu X, Yamauchi K, Saka S (2009) Chemical conversion of lignocellulosics as treated by two-step semi-flow hot-compressed water. In: Proceedings of the $3^{\text {rd }}$ International Conference on Sustainable Energy and Environment (SEE2009) incorporated with the World Renewable Energy Congress 2009 - Asia, 19-22 May, 2009, Bangkok, Thailand, pp 235-240.

13. Dence CW (1992) The determination of lignin. In: Lin SY, Dence CW (ed) Methods in lignin chemistry. Springer, Berlin, pp 33-39

14. Chen CL (1992) Nitrobenzene and cupric oxide oxidations. In: Lin SY, Dence CW (ed) Methods in lignin chemistry. Springer, Berlin, pp 301-312

15. Ehara K, Takada D, Saka S (2005) GC-MS and IR spectroscopic analyses of the lignin-derived products from softwood and hardwood treated in supercritical water. $\mathrm{J}$ Wood Sci 51: 256-261

16. Franck EU (1970) Water and aqueous solutions at high pressures and temperatures. Pure Appl Chem 24:13-30

17. Yoshida K, Kusaki J, Ehara K, Saka S (2005) Characterization of low molecular weight organic acids from beech wood treated in supercritical water. Appl Biochem Biotechnol 121-124:795-806

18. Ehara K, Saka S, Kawamoto H (2002) Characterization of lignin-derived products 
from wood as treated in supercritical water. J Wood Sci 48: 320-325

19. Takada D, Ehara K, Saka S (2004) Gas chromatographic and mass spectrometric (GC-MS) analysis of lignin derived products from Cryptomeria japonica treated in supercritical water. J Wood Sci 50: 253-259

20. Tsujino J, Kawamoto H, Saka S (2003) Reactivity of lignin in supercritical methanol studied with various lignin model compounds. Wood Sci Technol 37: 229-307

21. Saka S, Hosoya S, St-Germain FGT, Goring DAI (1988) A comparison of the bromination of syringyl and guaiacyl-type lignins. Holzforschung 42: 79-83 


\section{Figure legends}

Figure 1. Fractionation of the products from Japanese beech wood as treated by two-step semi-flow hot-compressed water.

Figure 2. Yields of fractionated portions of Japanese beech wood as treated in two-step hot-compressed water (wt\% on wood basis). Values in the parentheses refer to the percentage of lignin contents, a sum of KL and ASL, in the fractionated portion.

Figure 3. Yields of the lignin-derived products on original lignin basis from Japanese beech wood as treated by two-step semi-flow hot-compressed water (wt\% on lignin basis).

Figure 4. Gel permeation chromatograms of the water-soluble portions and the precipitates obtained from the first and the second steps of the two-step semi-flow hot-compressed water treatment of Japanese beech wood. (detector: $\mathrm{UV}_{205 \mathrm{~nm}}$ )

Figure 5. Yields of alkaline nitrobenzene oxidation products and the $S / V$ ratios determined for precipitates and residues in the first and second stage of Japanese beech as treated by two-step semi-flow hot-compressed water. * A sum of KL and ASL. Just comparison, untreated wood was also studied. 


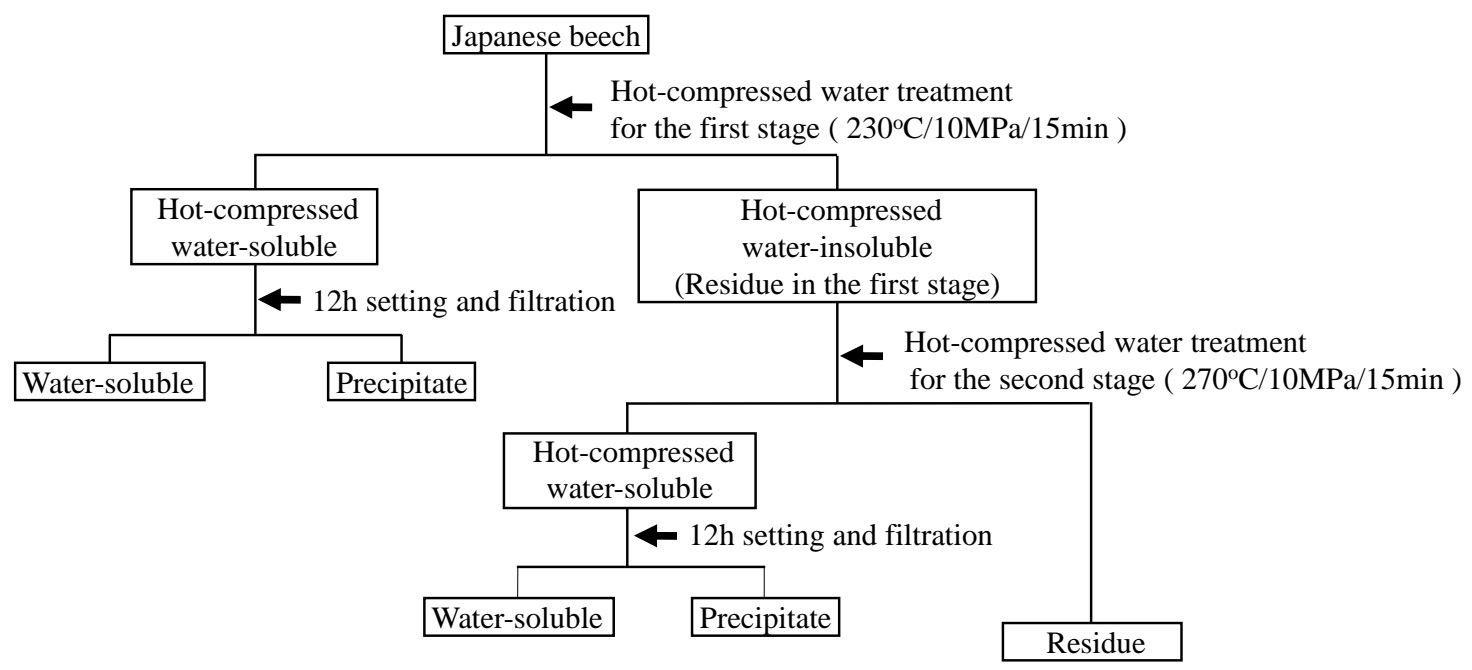

Figure 1. 


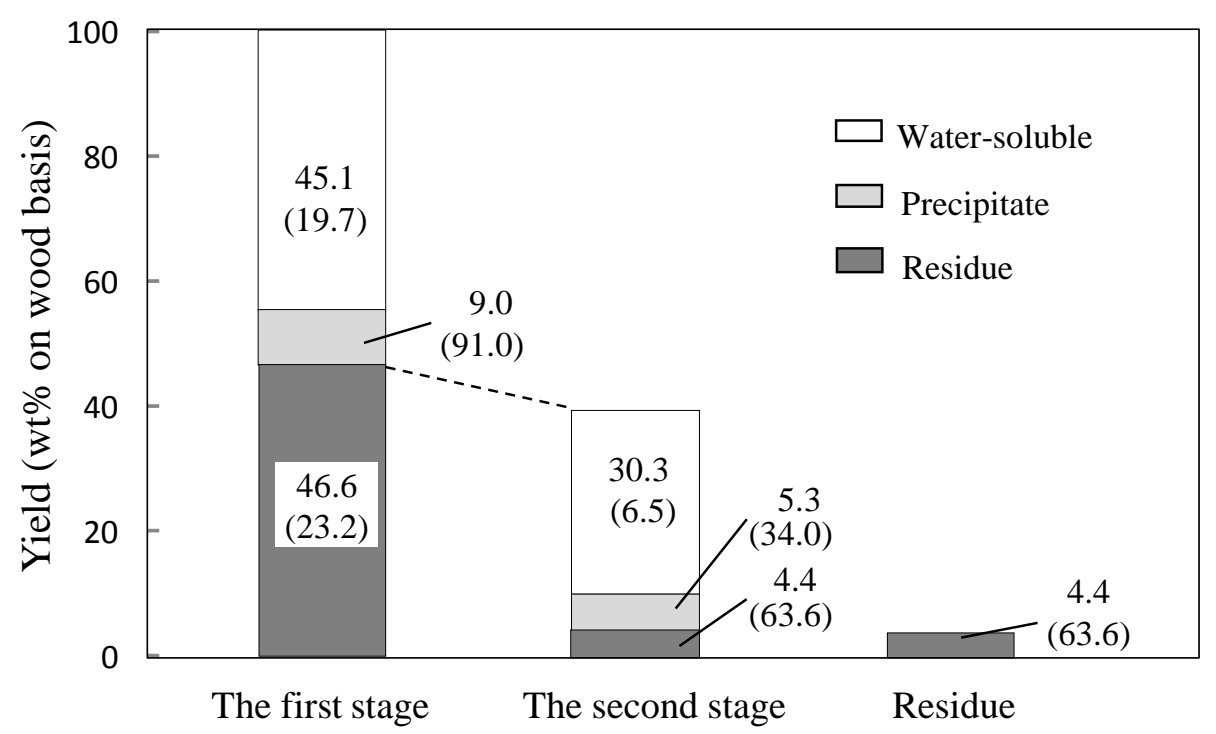

Figure 2. 


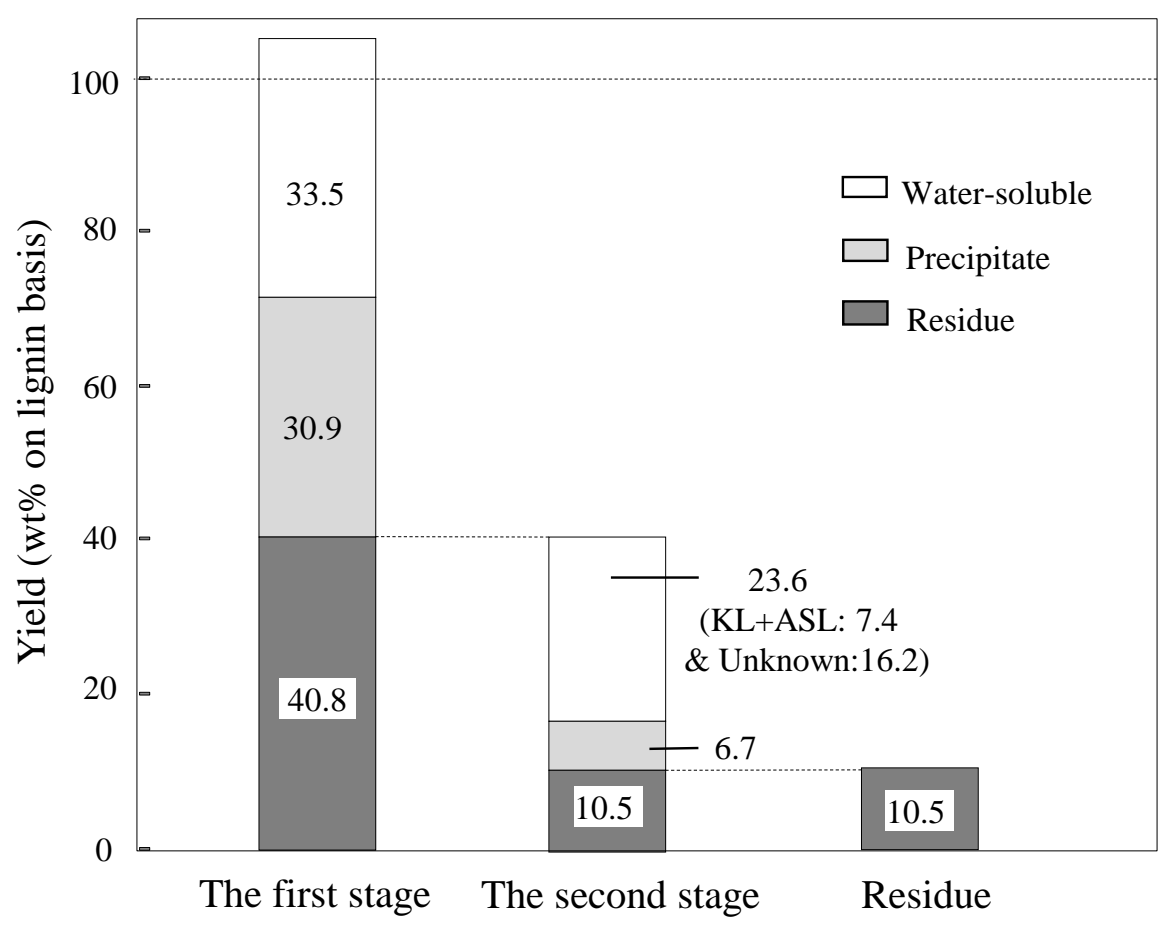

Figure 3. 


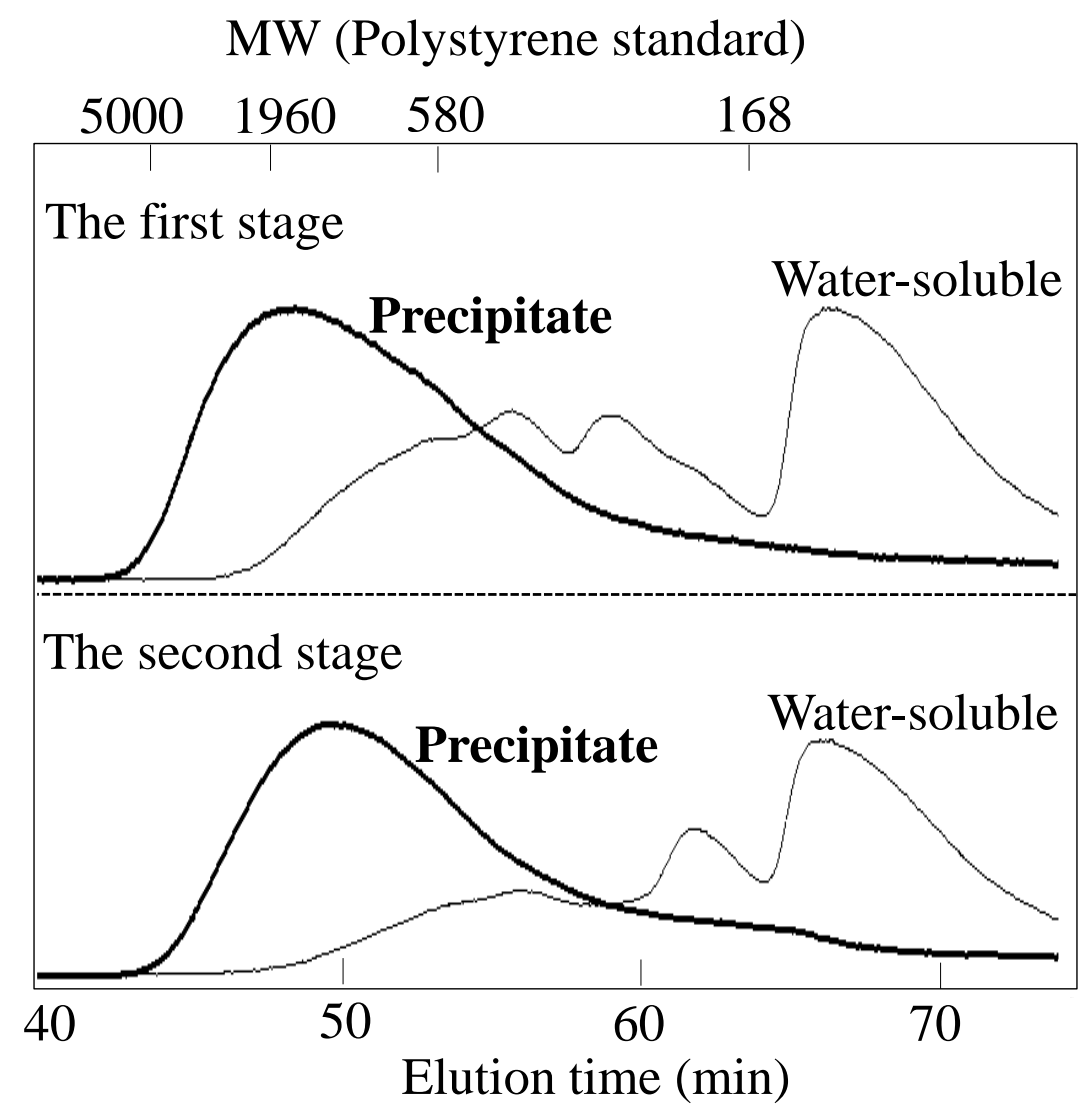

Figure 4. 


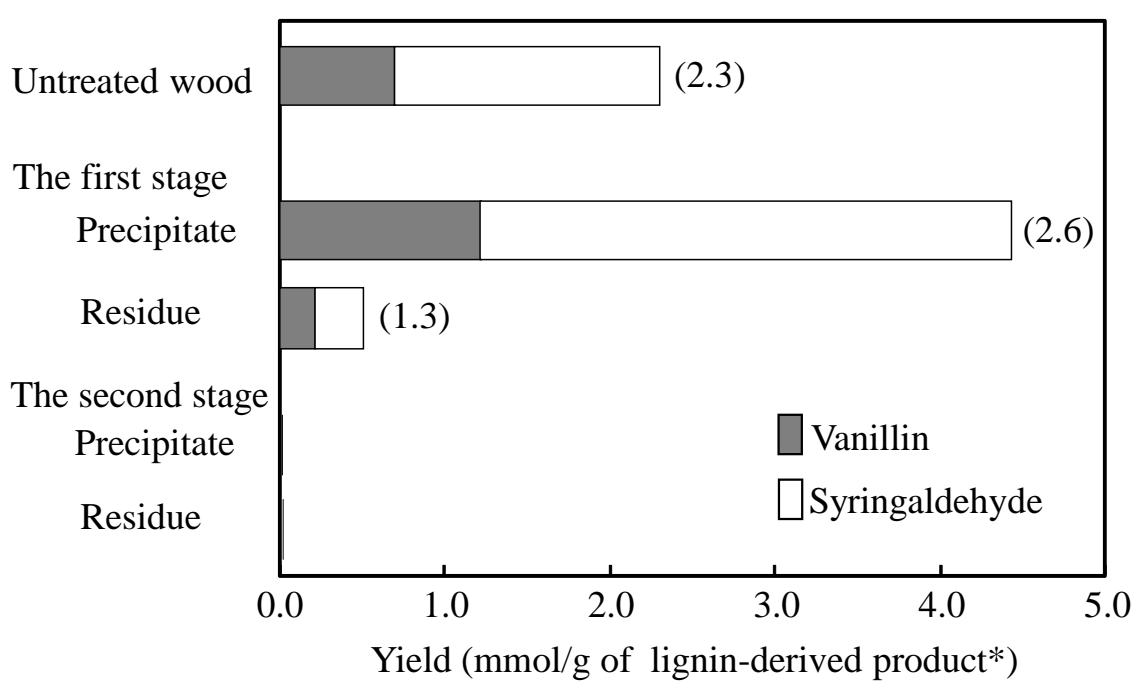

Figure 5. 